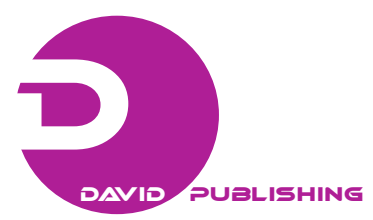

\title{
Generating a 3D Tool to Represent Graphically the Damages of Santa Barbara Castle (Alicante)
}

\author{
Víctor Echarri, A. B. González Avilés, J. Garabito, M. I. Pérez Millán, A. Priego \\ Department of Building Constructions, University of Alicante, University of Burgos, Spain
}

\begin{abstract}
Santa Barbara castle is one of the largest fortified complexes of the Spanish Mediterranean coast. Set in a strategic enclave in the city of Alicante. It has been transformed over the centuries since its origin, so that nowadays includes numerous buildings inside its area. The fortified area contains several lines bastioned and some medieval and Muslim fronts, composed of quadrangular towers. During the years 2007 and 2008, a research team composed of members from the University of Alicante, the University of Burgos and the Polytechnic University of Catalonia has developed a study on the conservation status of the Castle. This study has been funded through research grants from the Generalitat Valenciana (Project GV reference 2007/150), and an agreement with Manuel Peláez Foundation. We have generated a 3D object of the whole, composed by clouds of millions points, through laser-scanner in order to manage the analysis of the architectural element's conservation status that make up the huge fortified complex. This tool reduced greatly the architectural survey work, providing an extremely accurate. They were developed through the program Pointools View, generating JPEG files, which were imported from Autocad. Later we undertook a comprehensive making of photos - some 7,000 photographs, which we linked to the 3D object. Thus we have immediate access to the photographs of each element of the Castle from the program Pointools View with a simple click on each 3D element. The graphic representation of damages was done on screen with programs Pointools View and Autocad open simultaneously. This technique has meant better accuracy in the study of conservation status and has greatly reduced the time commitment.
\end{abstract}

Key words: Laser-scanner, Santa Barbara Castle, graphic representation of damages, Heritage Management.

\section{Introduction}

The intervention projects in the built heritage require a hard development of surveying and numerous field visits in order to collect information continuously about the status of stone facings, linings, foundations, etc. Once we have established the injuries suffered by the architectural complex, we must reflect each one of these lesions, with appropriate symbols, in a graphic document, specifying, stone by stone and area by area, the precise damage that is it. Then we carry out accurate measurements in order to evaluate budgets and establish a proper planning of work. Photogrammetry has been widely used to generate three-dimensional models by taking pictures of architectural element [1-3]. This method is considered

Corresponding author: Víctor Echarri, PhD, Architect, research fields: fortifications, military engineering, heritage. E-mail: victor.echarri@ua.es. as efficient tool to represent the forms geometrically well defined, but is impractical when these forms are complex geometric shapes. The use of laser-scanner is an alternative way to solve the generation of 3D models and the surveying in a more precise and faster way [4].

The laser-scanner can be sometimes an alternative or complement to the photogrammetric techniques. The building is automatically scanned with resolution that is required within the limits of the equipment. The shot can get usually 1,500 points per second, with their respective coordinates $(\mathrm{X}, \mathrm{Y}, \mathrm{Z})$ with respect to the laser-scanner situation, this speed can even be increased. Each point has assigned coordinates (R, G, B) projecting their geometric coordinates to a color imaging device that is coupled internal or externally to the scanner, following the model in projected perspective. A cloud of points is generated for each laser-scanner shot. All the shots can be processed together by taking a few references to overlap the 
different shots, getting a 3D object consisting of a point cloud. It is possible to incorporate color to this object, with the limitations of light that incises in each one of the shots, and taking into account that initially it does not apply color to the interstices between points (Fig. 1). The light conditions vary greatly during the scanning process when working outside.

You can generate a polygon model through processes of triangulation points, obtaining a mesh that conforms fairly close to the surfaces of the architectural element [5]. Better color resolution can be obtained using independently a high resolution digital camera. You can control its parameters and obtain a series of photographs, which may be superimposed subsequently on the triangle mesh, providing a great realism to the 3D model.

We have completed recently a study on the conservation status of the Santa Bárbara Castle, Alicante. The multidisciplinary research team had members from the Universities of Alicante, Burgos and Polytechnic University of Catalonia. The study was funded through grants from the Generalitat Valenciana (Project GV reference 2007/150) and an agreement with Manuel Pelaez Foundation. Santa Barbara Castle is one of the most important Spanish Mediterranean fortified complex. It's located in a strategic location on a rocky promontory that overlooks the coast. It was transformed over the centuries as the main fortress of the Alicante coast. His first traces are from the period of Muslim rule, although it is being carried out archaeological work nowadays in order to determine their origins. After a significant development experienced by Muslim masters, and the subsequent changes in the Christian Middle Ages, it suffered a major transformation in the late sixteenth century, when Philip II sent the most prestigious military engineers of the time for a modernization project of the castle. Military engineer Fratín and Vespasian Gonzaga planned and directed the works of the castle's north-eastern part, designing a bastioned front, so the fortified complex included Muslim areas allocated to store the crops and guard the cattle: the Albacar den Mig and the lower Albacar. Although we unknown the shape of this latter is very likely that Fratín maintained its layout. At the end of the seventeenth century it began other transformations motivated by the war with

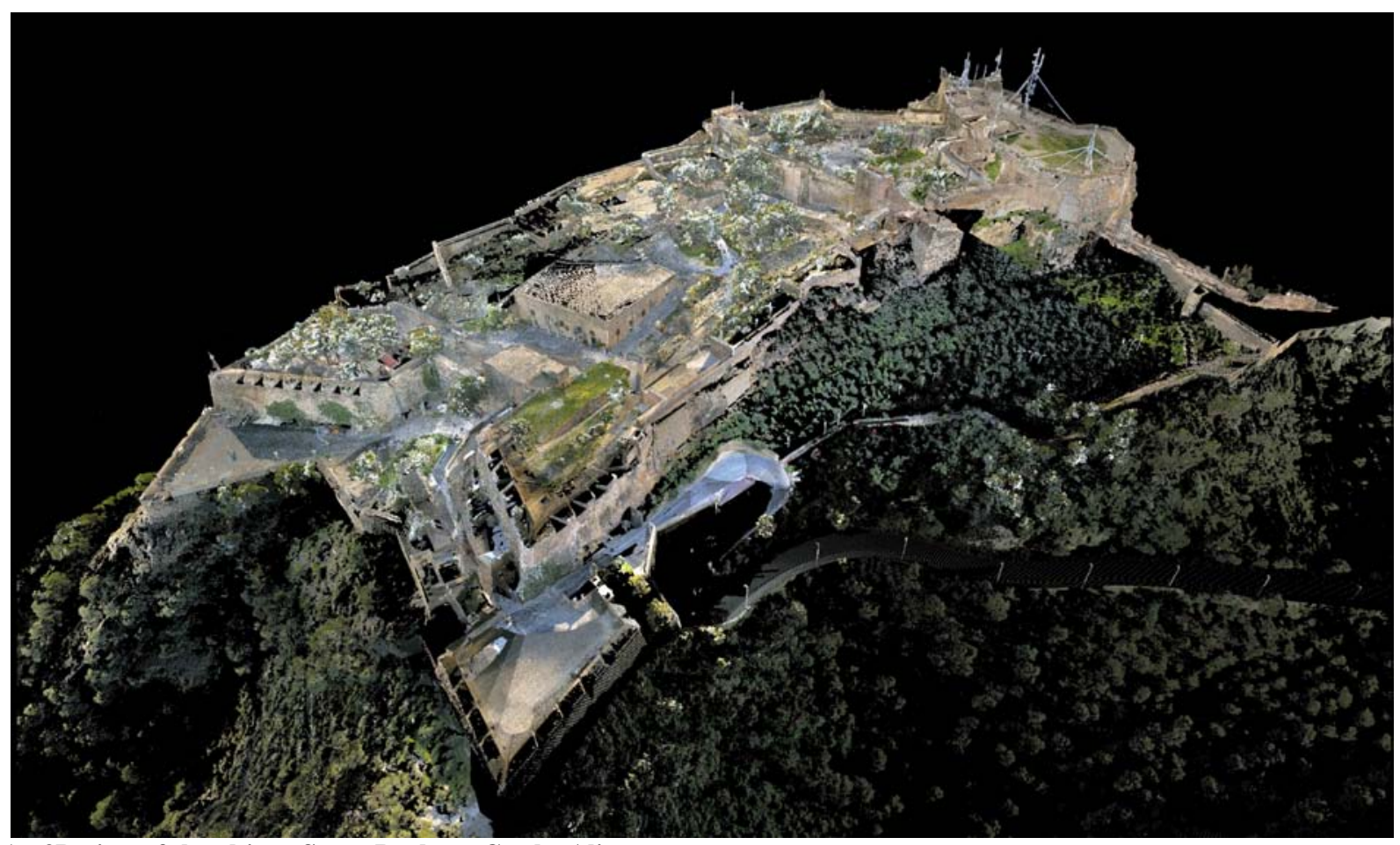

Fig. 1 3D view of the object, Santa Barbara Castle, Alicante. 
France. It commenced demolishing the top of the medieval towers of the Castillo del Macho and constructing a new wall around them. And underneath the bastioned front of Fratín was built an outer curtain and two low bastions. The Castle suffered the effects of a mine during the War of Succession in 1709, which caused the collapse of a bastion and the rupture of the higher cistern. This southern front of the castle, near the area of the Macho, was transformed with a curtain, but the bastion was not rebuilt because it had been eliminated the rock on which it was built.

This article describes the methodology applied to Santa Barbara Castle to carry out a study about the conservation status, with the graphic representation of the pathologies, and the use of the 3D generated object as a management tool through hyperlinks associated to the different architectural elements of this fortified complex.

\section{Methodology for Surveying}

Photogrammetry techniques require a considerable effort for fieldwork. It takes several weeks to reference a few hundred points from which it's possible to generate the perspectives of the building that can be improved with photographs, and adjusting and coordinating the points with which it was obtained the coordinates in reference lines. It could reduce the number of points referenced by using of some additional frontal photographs.

The laser-scanner provides far more information than the photogrammetry method and the field work is drastically reduced [6]. It has been shown in many cases, such as the present one in this article, and we will discuss below: Santa Bárbara Castle in Alicante. The clouds of points generated are treated properly in order to liberate them from the noise produced. Then, we overlap them properly according to coordinates $(\mathrm{X}, \mathrm{Y}$, $\mathrm{Z}$ ) for some points, and subsequently we treated them through software as Rapidform, Polyworks or Geomagic Studio. We will find vacuums in the data gathered in the various shots with the laser scanner, those elements to which the laser does not have access, as well as redundant or duplicate points, which must be treated in the second phase. We solve the adjustments of data through algorithms in order to adjust the points in the gaps; every software program has their own ones to solve such problems. Good planning of the positions of the scanner minimizes significantly these problems [7]. Through the software we can generate clouds of points with different resolutions like a filter, selecting points within a certain maximum distance, for example $2 \mathrm{cms}$, thus a better distribution of the resolution, since the laser scanner obtains more density of points in those elements that are closer and less on those further away. These clouds of points are generated depending on the resolution at which you want to work and the equipment available, and can be treated with software such as Pointools View 1.7 Pro or the version available for CAD to proceed to use them in the representation of lesions detected and analyzed in the architectural complex, or in the management of the information associated with the 3D object.

This is how it has been done in the present example, Santa Bárbara Castle in Alicante. First of all, it was the planning of the positions in which a priori the laser scanner would be located. Whereas the buildings and walls of the castle are situated in the highest point of Alicante city, we had to deal with this issue very carefully. In some elements, such as coronations of parapets or loopholes, it could not be obtained point clouds. Besides in some of the roofs was not possible to position the laser-scanner because of the security and the accessibility issues. We used a laser scanner Riegl LMS-Z420i for the data collection [8]. The work was done in two phases: in the first phase we took 120 shots and 60 in the second one, because it was required due to the magnitude of the built compound as well as the complexity of its architecture. We did not take shots inside the buildings. The clouds of points in the second phase were treated as described above, generating a cloud of points every $2 \mathrm{~cm}$ separated of $700 \mathrm{Mb}$ size. Later we employed the program Pointools View 1.7 
Pro to generate plans and general elevations, and plans and elevations of details of the various buildings and architectural elements of the castle (Fig. 2).

Given that in the year 2001 it was carried out the castle surveying through traditional techniques, and the laser-scanner a year ago, we can establish that the traditional system spent twelve weeks of work between data collection and delineation in the studio, while with the technique of laser-scanner it was made in just three weeks. In addition, given the geometric complexity of the castle, with significant level differences between the elements and buildings, it is clear that in no case could be a complete surveying of the castle but only the most relevant parts, so if we wanted to do the same with some minor elements would involve a very long time, while through the $3 \mathrm{D}$ object and a suitable software this task could be done in one day. We generated a total of 35 rectified elevation plans in 2D to be used for represent trough appropriate symbols pathologies detected in the walls and the architectural elements of the castle.

\section{Mapping of Pathologies: Santa Barbara Castle}

The job of represent graphically the damages of the Castle the year 2001 was huge due to the magnitude of the architectural compound, and the difficulties to be able to analyze and observe each one of the stones and the grouts of the castle while they were working in the studio [9]. On numerous occasions they had to re-take a shot in situ data. Nor it was easy to manage the search within the photographs file of each one of the elements. It was a job that was measured in a full year for a person, or about 1,500 hours. They worked with Autocad, and they used various symbols to describe the pathologies detected: stone weathering, soil deposits, erosion, metallic staining, vegetation, biological surface soiling such as lichens and moss, loss of grouting mortars, coating detachments, cracks, partial loss of ashlars and masonry and efflorescence.

\subsection{Management to Access the Photos via the $3 D$ Object}

In this second phase of the project, conducted in 2009, the goal was to redo a pathologic study and about the castle conservation. We started from the previous experience, but the challenge was to achieve a much precise and detailed mapping, since the difficulties described above did impossible to reach these goals with the traditional techniques.

We proceeded to this job using the $3 \mathrm{D}$ object as information management and surveying, as we described in the previous section. For this we took 7000 photos of the castle, a comprehensive photographic report, which only excluded some elements which there was no access due to the topography. No doubt it was a sufficiently clear visual picture of each one of the stones of the castle's exterior walls.

We proceeded to carry out hyperlinks of the photographic archives associated with the 3D object, so that it was accessible the selection of photographs of

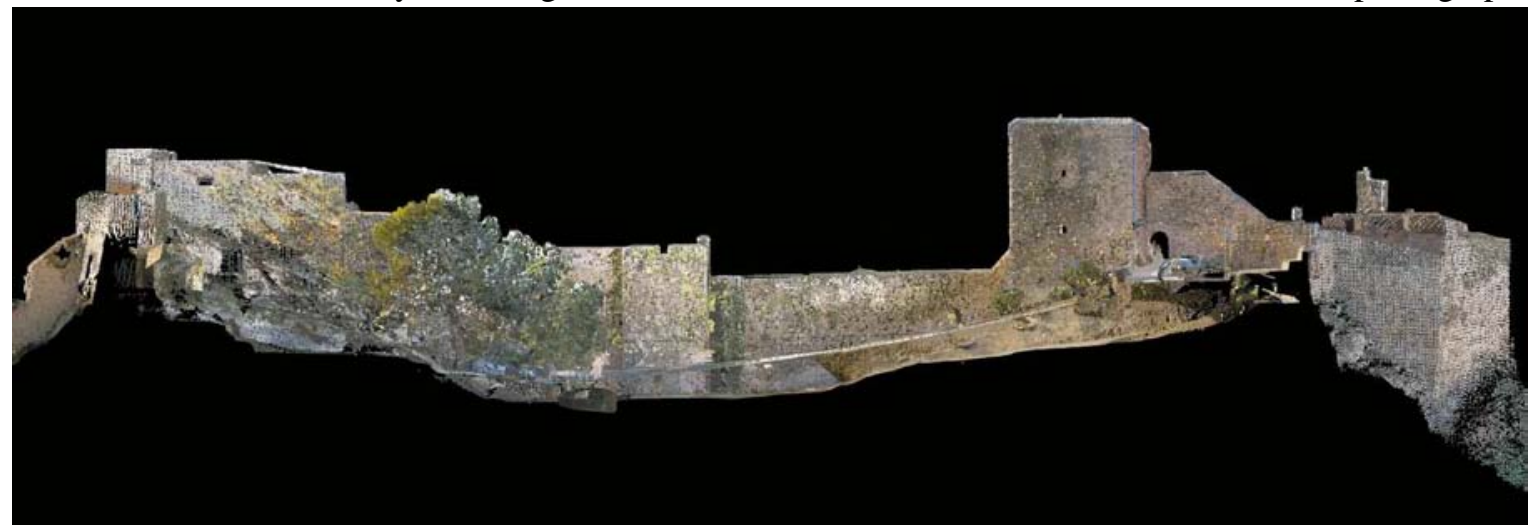

Fig. 2 Front elevation of the castle with the Santa Catalina tower, Muslim style. 
the item which lesions were depicted, with a simple click on the screen (Fig. 3). They were 250 hyperlinks to folders that have between 10 and 30 photographs. To proceed to the graphic representation on plans of the pathologies we used simultaneously the programs Autocad and Pointools View 1.7 Pro, displaying pictures, the 3D object and the plans under development. Moreover, the use of the 3D model as an access tool to information made possible to link the history of interventions in each one of the elements, mineralogical analysis results of stone and mortar, old maps preserved in military and administrative files relating to those items, etc...

\subsection{Graphic Representation of Pathologies: Searching} for a Closer Approaching to Reality and More Accuracy

Elevation plans were generated in an importable Autocad format through Pointools View 1.7 Pro software. In the process of delineation damages we looked for accuracy -the elevation plan generated through the 3D object had a great precision, with an average deviation of $10 \mathrm{~mm}$ for each facing of $50 \mathrm{~m}$ length- and that the information transmitted the reality of the facings. The laser scanner provided a picture close to reality. We thought that when we did the graphic representation of damages, we had to use a technique that respected the reality vision of the stones and mortars while determined the lesions at the same time. To do this pattern types were generated in different colors - one color for each type of lesion made out of small dots that create transparency. The final aspect of the plans complied with the realism, at the same time that transmitted the information that we wanted to demonstrate and quantify (Fig. 4).

While in the year 2001 a person spent a whole year to do this job, through this work method with the access to the photographic information it produced the same result in a three months time. Moreover the costs were drastically reduced, the graphic representations had greater accuracy and the final result got more reliability.

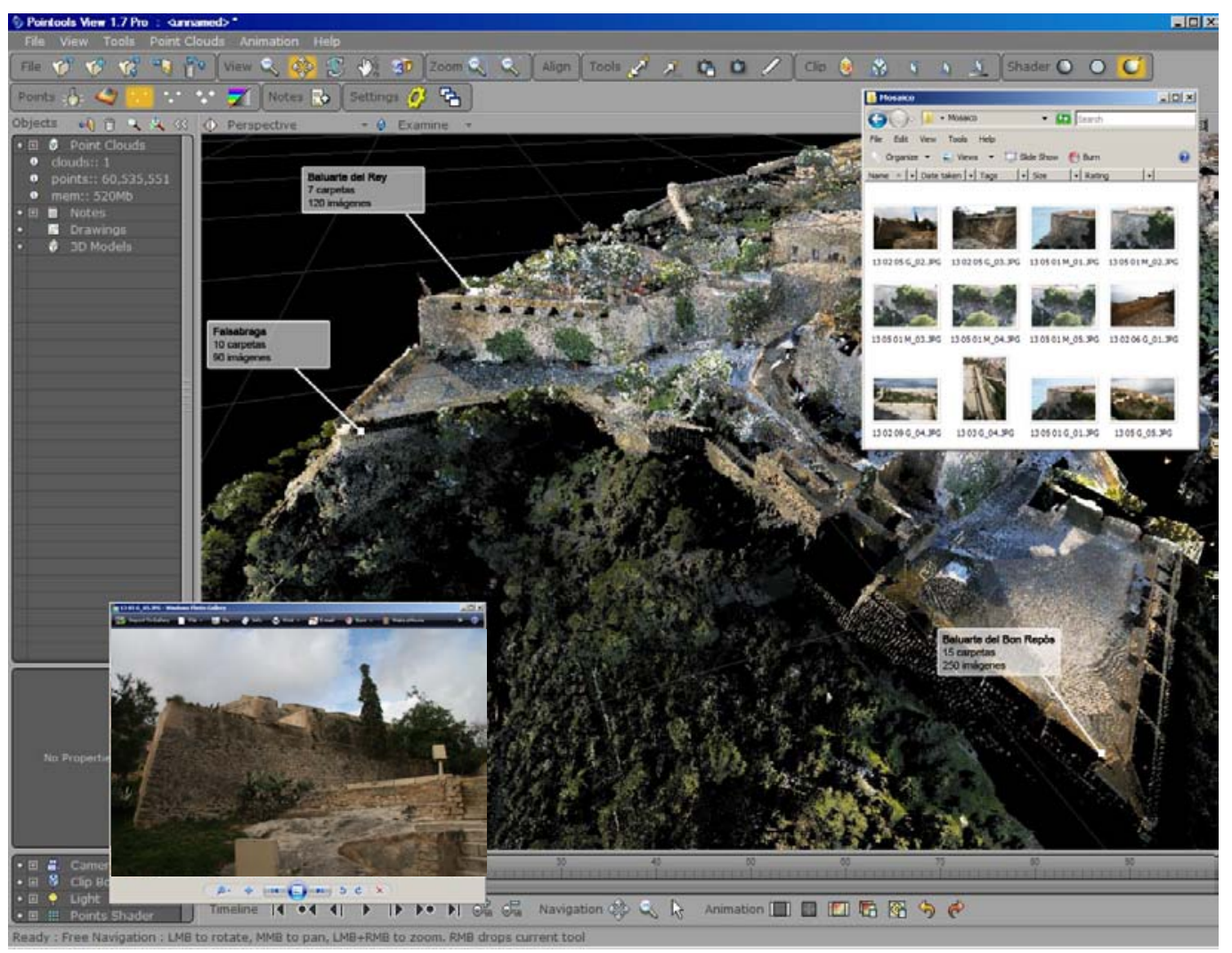

Fig. 3 Screen view of the 3D object and folder of photographs associated through hyperlinks. 


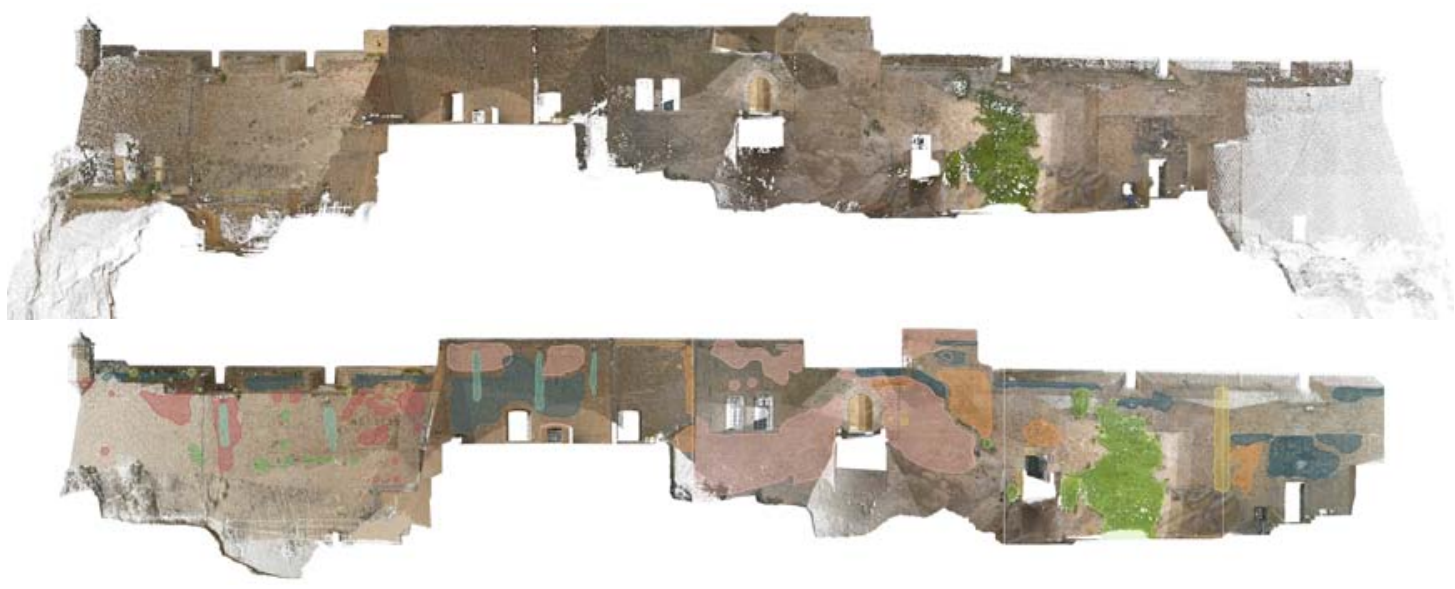

Fig. 4 North-east elevation of Macho del Castle, before and after the graphic representation of pathologies.

The result was satisfactory for most of the 35 plans generated, but not for some in which the laser-scanner was unable to collect enough point's density, due to some natural obstacles or inaccessible areas. To solve such problems we thought in using real photographs, processed through photogrammetric techniques for orthogonal projection and attach them to the elevated plans generated by the laser-scanner. Once the images are overlapped it is easy to deform proportionally the photograph to match with the reference point. This task had to be done by taking apart the elevation plans and adjusting the pictures by parts, due to the geometric complexity of the facings. This task was laborious and we only carried out this technique in those elevations where it lacked sufficient information. Since the images generated by the point clouds had a certain density, a point every $2 \mathrm{~cm}$, the photographs were treated to get a similar density, depending on which would be the scale to represent each one of the planes. The final result was an image closer to reality than the image directly generated by the laser-scanner, due to the aspects of color association described above (Fig. 5).

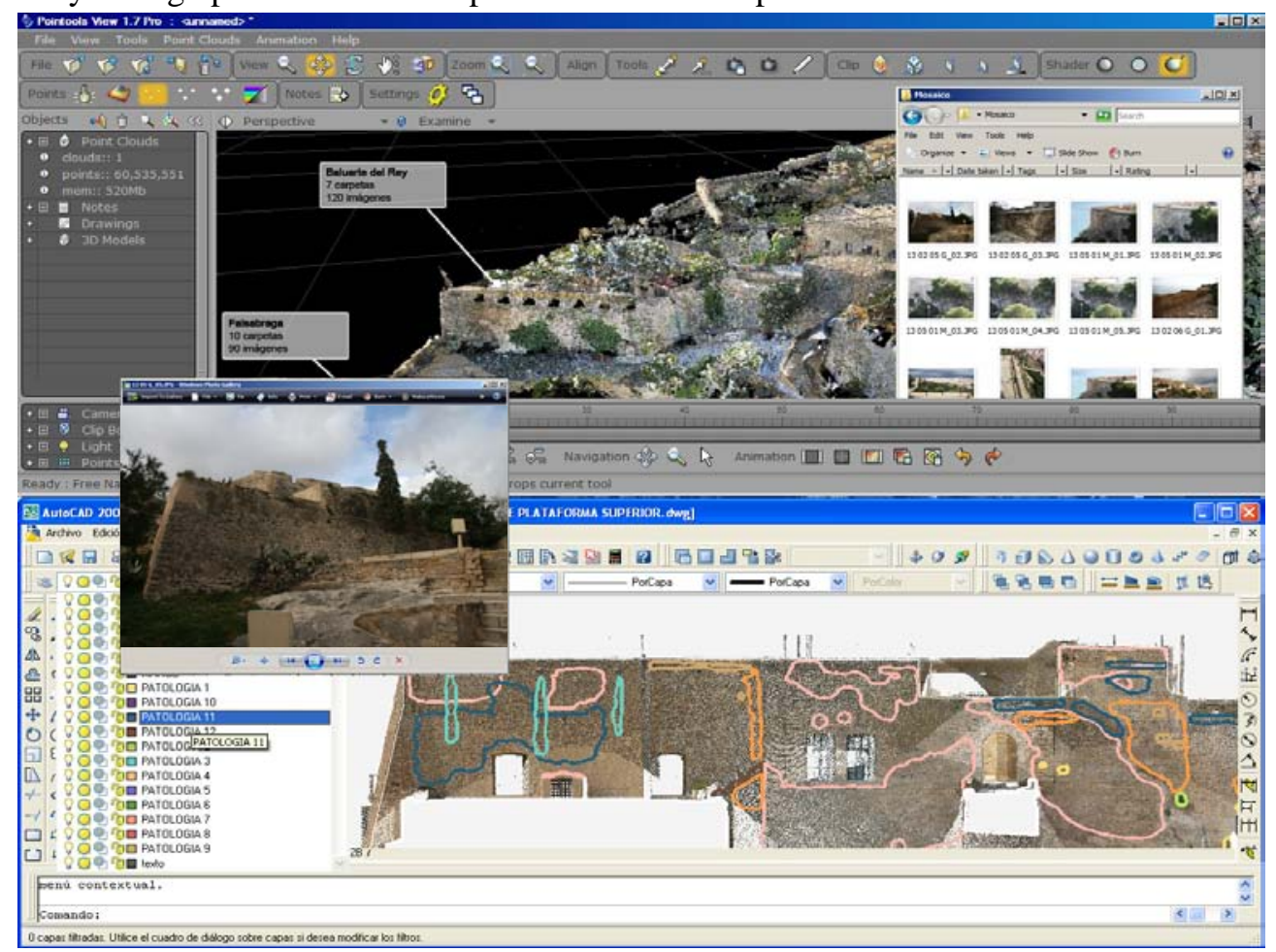

Fig. 5 Methodology for pathologies representation with CAD while accessing to related photos. 


\section{Conclusions}

The use of the laser scanner technique is shown as a very suitable tool for the implementation in intervention projects in the built heritage, especially when it comes to a complicated architectural compound, due to its geometry, volume and fragmentation. The precision of the points cloud of the $3 \mathrm{D}$ generated object, the versatility of its use in order to obtain 2D drawings, and its close proximity to reality in terms of chromatic resolution allow to obtain more accurate plans with the pathologies representation, more appropriate graphically with the architectural reality and in a very less time than that used by traditional techniques.

The use of appropriate software, such as the program Pointools View 1.07 Pro, allows converting the 3D object into an information management tool through the creation of hyperlinks. This way we can have immediate access to the intervention history in each architectural element, information about the characterization of stone and mortars, and actual photographs with sufficient detail to observe from the display the conservation status of the monument, stone by stone. We can use simultaneously open on-screen the 3D object, the associated photographs and the Autocad program in order to represent graphically the pathologies of each facing, in a more efficient, more dynamic and faster way, especially in large-scale architectural complex.

In areas where the laser scanner may not be available for obtaining point clouds we can resort to the processing of photographs, adjusting by photogrammetry treatments to the plans generated by the 3D object. His subsequent graphic processing trough dot patterns by programs such as Photoshop, can provide highly realistic images, while the damages in the architectural elements are depicted

\section{Acknowledgements}

We wish to thank to the Generalitat Valenciana, through the Ministry of Education, and the Manuel Peláez Foundation, without which we could not have carried out this research. We also thank the Centre de Política del Sòl i Valoraciones of the Polytechnic University of Catalonia, led by Josep Roca, the work in the collection of data and technical advice.

\section{References}

[1] P. Arias, et al., Methods for documenting historical agro-industrial buildings: A comparative study and a simple photogrammetric method, Journal of Cultural Heritage 7 (2006) 350-354.

[2] H. M. Yilmaz et al., Documentation of historical caravansaries by digital close range photogrammetry. Automation in Construction 17 (2008) 489-498.

[3] P. Salonia et al., Multi-scale cultural heritage survey: Quick digital photogrammetric systems, Journal of Cultural Heritage 10 (2009) e59-e64.

[4] G. Pavlidis et al., Methods for 3D digitization of cultural heritage, Journal of Cultural Heritage 8 (2007) 93-98.

[5] P. M. Lerones et al., A practical approach to making accurate 3D layouts of interesting cultural heritage sites through digital models, Journal of Cultural Heritage 11 (2010) 1-9.

[6] S. Lisinger, 3D laser versus stereo photogrammetry for documentation and diagnosis of buildings and monuments (pro and contra) in: CIPA 2005, XX International Symposium, Torino (2005).

[7] J. Armesto et al., Modelling masonry arches shape using terrestrial laser scanning data and nonparametric methods, Engineering Structures 32 (2010) 607-615.

[8] N.Yastikli, Documentation of cultural heritage using digital photogrammetry and laser scanning, Journal of Cultural Heritage 8 (2007) 423-427.

[9] F. Bruno et al., From 3D reconstruction to virtual reality: A complete methodology for digital archaeological exhibition, Journal of Cultural Heritage 11 (2010) 42-49. 